\title{
Being there and reconnecting: midwives' perceptions of the impact of Mindfulness training on their practice
}

\author{
Authors: Hunter L, Snow S, Warriner S
}

\section{ABSTRACT}

Objective: To ascertain how midwives perceived attending a mindfulness course impacted on their professional practice, particularly in regard to any stress they experienced at work.

Design: A qualitative study using Interpretive Phenomenological Analysis. Semi-structured interviews were conducted with nine midwives.

Setting: A large maternity Trust in the United Kingdom.

Intervention: An eight-week Mindfulness course, adapted from Mindfulness-based Cognitive Therapy.

Findings: Four superordinate themes were identified: 'being challenged and committing', 'containing the self', 'reconnecting', and 'moving forward with confidence'. Focusing on the present moment enabled participants better to identify the boundary between self and other. This led to an increased sense of control and a reconnection with and reframing of relationships with colleagues and the women in their care.

Key conclusions: Mindfulness may provide an effective way to address the high levels of stress, role dissatisfaction and workplace bullying found in Midwifery, by improving both the working environment and patient care. The pivotal role of positive workplace relationships in this process resonates with other nursing research and with contemporary philosophical thought.

Relevance to clinical practice: This study adds to a body of evidence which suggests investing in the wellbeing of midwifery staff improves both job satisfaction and women's experiences of care.

What does this paper contribute to the wider global clinical community? 
- Mindfulness may enable practitioners to reconnect with themselves, their colleagues and the women in their care

- Supportive workplace relationships could mitigate against stress and burnout, and may be a prerequisite for improved patient care

- Investing in staff wellbeing is likely to improve practice, care and retention

Keywords: Midwives, Mindfulness, Stress, Burnout, workplace relationships

\section{INTRODUCTION}

Mounting evidence suggests that midwives in different countries are experiencing increasing levels of stress, burnout and unhappiness in their work. A recent survey by the Royal College of Midwives ( $R C M$ ) in the UK, which garnered 1,361 responses, found that $48 \%$ of midwives and maternity support workers felt stress every day or most days (Royal College of Midwives, 2016). Fifty six registered midwives in Australia completed the Maslach Burnout Inventory; results showed that over $60 \%$ experienced moderate to high levels of emotional exhaustion, $30 \%$ low personal accomplishment and 30\% depersonalisation (Mollart, Skinner, Newing, \& Foureur, 2013). A survey of 442 midwives in Japan found that $25-35 \%$ reported high stress levels (Sato \& Adachi, 2013). Worklife balance and role dissatisfaction are cited among the principal reasons behind many midwives intending to leave or leaving the profession (Pugh, Twigg, Martin, \& Rai, 2013).

The literature reports a number of factors underlying high stress levels in maternity settings. Principal among these are chronic levels of understaffing, workload, workplace bullying, and the stress and psychological trauma resulting from attending traumatic births and being involved in litigation claims. Understaffing and workload emerged as key themes in the RCM survey, with $78 \%$ of respondents citing workload, $76 \%$ staff shortages, and $65 \%$ insufficient time to do their job, as direct causes of stress (Royal College of Midwives, 2016). A literature review found midwives, and perhaps more worryingly, midwifery students, were subjected to workplace bullying, or horizontal violence, 
in a number of different countries (Majhenic \& Mivsek, 2012). A third of the respondents to the RCM survey said that they had experienced harassment, bullying or abuse from colleagues in the last 12 months (Royal College of Midwives, 2016); and in Australia a survey of 52 student midwives reported that $30 \%$ experienced intimidation, $17 \%$ verbal abuse, $3 \%$ physical abuse and $3 \%$ sexual harassment whilst on placement (Mckenna \& Boyle, 2016). Stress as a result of attending traumatic births is reported in several studies; an American survey of 473 certified nurse midwives, for example, found that $29 \%$ reported high or severe secondary traumatic stress, and $36 \%$ screened positive for post-traumatic stress disorder, as a result of being involved in a traumatic birth (Beck, LoGiudice, \& Gable, 2015). The number of midwives experiencing stress as a result of being involved in litigation claims is likely to rise as the number of claims continues to increase (Robertson \& Thomson, 2014).

Work-related stress and anxiety is not only having a deleterious effect on midwives, it also impacts negatively on women's experiences of care, making it all the more important that steps are taken to halt this growing problem (L. Hunter, Magill-Cuerden, \& McCourt, 2015; Royal College of Midwives, 2016). Although none of the contributing causes of stress and distress in midwifery are easily resolved, there is evidence that they can be mitigated if organisations take steps to support and care for staff (Royal College of Midwives, 2016). One strategy that has been tried to decrease stress and improve wellbeing among nurses and midwives is Mindfulness training (Guillaumie, Boiral, \& Champagne, 2016; L. Hunter, 2016; Warriner, Hunter, \& Dymond, 2016). Mindfulness uses meditation techniques to bring attention to and observe what is happening in the present moment (Chiesa \& Serretti, 2009; Warriner et al., 2016). It promotes non-judgemental acceptance and curiosity regarding one's own and others' thoughts and emotions, including ruminative and destructive thought patterns (Ludwig \& Kabat-Zinn, 2008). Randomised controlled trials and prepost-test studies have shown that mindfulness decreases stress and anxiety among nurses and midwives, at least in the short term (Guillaumie et al., 2016; Warriner et al., 2016). There is, however, a lack of qualitative research investigating how mindfulness is impacting nursing and 
midwifery practice (L. Hunter, 2016). It is increasingly acknowledged that, while quantitative research can establish whether or not an intervention works, complex interventions in particular require qualitative enquiry in order to establish why and how they work, and for whom (Harden \& Health, 2010; Tariq \& Woodman, 2010). A synthesis of the limited qualitative literature available suggested that mindfulness techniques enable nurses and midwives to create a quiet mental space where they can focus and plan before responding to events in a calmer and more measured way (L. Hunter, 2016). This study aims to explore how midwives who attended a Mindfulness course perceived that it impacted on their professional practice, particularly in regard to any stress that they might experience at work. An increased knowledge of the perceived impact of mindfulness training on midwives' working lives will facilitate theory development around enabling mechanisms triggered by mindfulness practice in maternity settings, and facilitate a more complete assessment of the suitability of this strategy for reducing workplace stress among midwives.

\section{METHODS}

Midwives in a large UK NHS Trust, overseeing around 10,000 births per year, were invited to take part in semi-structured interviews. Midwives were eligible to participate if they had attended a Mindfulness course either at or outside work. Three eight-week Mindfulness courses had been made available to maternity staff at the Trust in the preceding year. Each course followed the Mindfulness: finding peace in a frantic world programme, adapted from Mindfulness-based Cognitive Therapy (Williams \& Penman, 2011). This programme consists of eight 60-90 minute group sessions designed to introduce different formal and informal Mindfulness practices to people who are not familiar with Mindfulness and do not have a clinical diagnosis of stress or depression (Warriner et al., 2016).

Further details, and the pre-post-test analysis of the courses run at the Trust, are reported elsewhere (Warriner et al., 2016). Midwives who had attended the Trust courses were sent an email invitation to participate in this study. The email included a Participant Information Sheet and contact 
details for the Principle Investigator (PI) (author one) so that potential participants could contact her with any questions or to indicate a willingness to take part. Posters were displayed in maternity units across the Trust so that midwives who had attended courses elsewhere also had the opportunity to participate. Ethical approval for the study was received from the lead author's university.

This study was informed by the principles of Interpretive Phenomenological Analysis (IPA), an approach which aims to understand the significance of particular events or experiences to individuals (Brocki \& Wearden, 2006; Smith \& Osborn, 2008). IPA combines empathic hermeneutics (an undertaking to attempt to understand participants' interpretations of experiences and events without judgement) with an in-depth and critical examination of data (attempting to see beyond the face value of what is said and expose underlying meanings). It favours semi-structured interviews as they allow participants to identify and explore salient themes, and enable the researcher and participant to engage in a dialogue in order to reach a mutual understanding of the participant's story (Brocki \& Wearden, 2006). This dialogue is the start of the process of interpretation and analysis (Roberts 2013). An interview schedule consisting of open questions and prompts was developed by (author 1), with feedback incorporated from (author 3). The schedule began by asking participants to talk about what they remembered about their mindfulness training, in particular what they found useful or challenging, and whether they still used any of the practices. It then moved on to ask them to reflect on whether and how the course had affected their perception of themselves as a practitioner, whether they now dealt with stress or stressful events differently, and any ways it had impacted on their relationships with colleagues or the women in their care. Interviews were conducted at a place and time of the participant's choosing (usually a quiet room at their workplace or at the lead author's university). Written informed consent was obtained before interviews commenced.

A distinctive feature of IPA is a detailed examination of a set of case studies - rather than present an overview of identified themes, it seeks to retain a sense of the individual narratives that make up the 
overall picture (Smith \& Osborn, 2008). Small sample sizes are used, allowing an in-depth exploration of each case. Rather than attempting to reach data saturation or generalise findings, IPA seeks to produce a detailed and coherent account which is clearly grounded in the words of the participants, sheds light on the broader context and can influence and contribute to theory building (Pringle, Drummond, Mclafferty, \& Hendry, 2011; Smith \& Osborn, 2008). The current study sought to recruit eight-ten midwives. It was thought that this number was sufficient to allow common themes to be identified across transcripts while still enabling an in-depth exploration of individual cases.

There is no set format for analysing data in an IPA study. However, Smith and Osborn (2008) stipulate that analysis should move from the descriptive to the interpretive, and transcripts should be analysed individually to identify themes and explore meaning on a case-by-case basis before data are combined. In the current study interviews were audio-recorded and transcribed verbatim. An inductive process was then undertaken whereby each transcript was read a number of times and a commentary of interesting, significant or recurring points was developed in the margin of the transcript. These comments were then used to identify themes. The process was highly iterative to ensure that each theme was grounded in the data. In order to give the reader an insight into the participants' backgrounds and experiences, a summary profile of each transcript was produced, identifying salient points and giving some information about each participant (see Table 1). Participants were invited to comment on their profile. NVIvo 10 software was used to generate and combine themes across transcripts, noting divergences as well as convergences. Themes were clustered into superordinate themes which were critically interrogated by all three authors, who then met to discuss and agree a more in-depth interpretation of the data. This process enabled us to see that behind the participants' narratives was a common thread of the boundaried and situated self. Becoming aware of this situated self could be disquieting initially, but awareness of the boundary between self and other brought control and an ability to contain the self and connect with those around you in a deliberate, meaningful and mutually beneficial way. 
IPA recognises that the researcher is at the centre of the analysis, and inevitably brings her own conceptual world into the process (Brocki \& Wearden, 2006). The PI in the current study, who conducted all the interviews, is a midwifery lecturer who had also attended a Mindfulness course. This enabled her to establish a rapport with the participants, but also carried the risk that she might privilege her interpretation of her experience over that of the participants. In addition to the analysis process described above, additional measures were taken to ensure that the findings represent the participants' views and experiences as closely as possible. These included the PI employing a reflexive, open-minded approach, allowing the data to challenge and change her own world view; the use of concurrent member checking during the interviews (using phrases such as 'my understanding of what you are saying is...') to enable participant and researcher to reach a mutual understanding; and a selection of anonymised transcripts being independently read and coded by a third party (author 2).

\section{FINDINGS}

Nine midwives elected to take part in the study. Each one was interviewed once, with interviews lasting between 12 and 48 minutes (mean 31.3 minutes). The 12-minute interview was given by a midwife (Petra) who did not want to reflect on her experiences in depth. It is included in the analysis as it gives a different perspective. All of the participants had attended one of the three Mindfulness courses at the participating Trust. They were a mix of full and part time midwives working in community or hospital settings and had been qualified for between nine months and 31 years. For most of the participants, the Trust Mindfulness course was their first experience of Mindfulness. Further details about the participants are outlined in their individual profiles in Table 1 below. Pseudonyms have been used to protect anonymity.

Four superordinate themes were identified, some of which contain sub themes (see Table 2). The superordinate themes were 'being challenged and committing', 'containing the self', 'reconnecting' and 'moving forward with confidence'. These themes illustrate how, although participants' 
responses to mindfulness were individual, it initiated an awareness of self and of the self as a situated entity. Although this could be disquieting initially, it could give participants increased control over their thoughts and actions, and facilitate a reconnection with colleagues and their professional identity which helped participants to cope with workplace stress and reframe their working lives in a positive light.

\section{Being challenged and committing}

This theme contains two sub-themes: 'discomfort' and 'keeping going'.

\section{Discomfort}

Looking back, participants described feeling 'peaceful' and 'calm' during their Mindfulness classes. However, it was also evident that on occasion the course could make participants feel uncomfortable. Levels of discomfort ranged from Rebecca feeling 'a bit stupid' when trying out mindful movement, through Jade's 'not see[ing] the point' of a programme perceived as 'alternative' and 'hippy', to Phoebe's guilt when confronted with her feelings about daily activities:

'So one of the exercises was to look at things that we had done through the day...that um we enjoyed and didn't enjoy... the things that I didn't enjoy were things that I was embarrassed not to enjoy like getting my son out of the door in the morning... I feel really bad that I don't enjoy that' (Phoebe).

Participants were used to being busy and stressed; to different degrees that busyness had become a cloak protecting them from reflecting on aspects of their lives. Although the course was described as an 'indulgence', and there was a level of guilt at taking time out, suspending busyness could be challenging and frustrating:

'If I'm doing a mundane task, then I use that mundane task to be thinking about something else... [I] can't keep my mind focused on cleaning teeth, or being present while I'm cleaning teeth, or whatever you're supposed to do while you're cleaning teeth' (Sophie). 
Most participants persevered and were able to find some mindfulness techniques they considered helpful and beneficial (perhaps unsurprisingly, the quicker and more practical exercises such as the three-minute breathing space were the most popular). Petra and, to a lesser extent, Phoebe, disengaged from the process however:

'I wasn't terribly good at doing the homework, and I didn't read the book... I'm not sure that it was really for me' (Petra).

\section{Keeping going}

There was a recognition that, in order to gain any benefit from Mindfulness, people needed to commit to the concept and incorporate regular practices into their lives. In particular, practising mindfulness when people were not feeling stressed would ensure that it was there for them in times of need:

'You have to do the, the practices when you're not under stress... so that when you are, you know what to do. So if you're only relying on your Mindfulness techniques when you're experiencing problems, you're not gonna have the um, the skill necessarily to do it because you haven't been practising' (Gill).

There was a consensus that regular Mindfulness refresher sessions would help participants continue to use the techniques learnt on the course, as sustaining Mindfulness practice in a busy and stressful working environment was difficult:

'I need reminders, so I probably need a monthly update or something like that, where I'd go to a class, and yea...a half an hour practice, or you know, even a 5 minute...' (Emma).

\section{Containing the self}

The next two themes, 'containing the self' and 'reconnecting', attempt to show how mindfulness impacted on participants' lives. Although most participants pointed to tangible benefits in their 
personal and work lives, the effect ranged from negligible (Petra) to 'life-changing' (Rebecca). Some expressed a note of caution about attributing any changes directly or solely to Mindfulness:

'It's really hard to know whether that's the Mindfulness or general things that are going on... it's probably a combination actually' (Emma).

'Containing the self' illustrates how Mindfulness gave rise to a heightened awareness of self, and of the boundaries of self. There was a sense of centring and grounding the self, which, by highlighting the boundary between self and other, enabled participants both to see and to gain a sense of control over how they felt and acted within their environments:

'You're aware of yourself and how you feel and, and - you're there, as such' (Jade).

There are four sub-themes within 'containing the self': 'centring the self', 'focussing', 'stepping back', and 'taking control'.

\section{Centring the self}

The breathing techniques participants learnt on the Mindfulness course enabled them to gather their thoughts, let go of stresses and focus in while driving to work or before starting a clinic, attending a home birth, or trying to build a relationship with a woman in challenging circumstances:

'So it's good to just, you know, 'right, stand outside the door, just let that go. Let everything go, just, just breathe and just walk back in as if you're starting all over again" (Jade).

There were occasions when participants had to remove themselves from a situation and go somewhere else to calm down, but they were now able to use their 'time out' to re-group, rather than continue to feel stressed:

'But I still will take myself off when it's really really busy. Rather than take myself off into the drug room and cry, I might just go in and just focus on my breathing' (Sophie). 
Breathing techniques were also frequently employed to cope with slow or malfunctioning technology:

'A particular thing is switching on the computer... it does make me think 'right, this has got to happen, I've got to wait for it to come on, so I could just sit quietly and just focus for a minute, and just breathe" (Emma).

\section{Focussing}

Mindfulness enabled participants to focus in on individual encounters or activities, and control the mind's tendency to worry about what might be going on elsewhere or ruminate over events:

'I know what's going on outside [the room], but I can, I can shut my mind off from it... So unless someone actually says 'we need you out here', or there's an emergency buzzer... I can shut myself off' (Sophie).

'You know not to sort of be negative in your thinking and let your autopilot take control, and not to be doing that um sort of, internal chatter about 'oh, they're gonna think I'm so useless'... I think it's being aware of that internal chatter and that autopilot and thinking 'ah, there I go', you know, and stopping yourself' (Nadia).

Focussing in on the present moment enabled participants to cope better with stress:

'It was just giving you that space, even if it was just briefly, to sort of, you know, reduce what you're experiencing' (Gill).

Emma, Rebecca and Sophie all described how focussing in had given them a genuine inner calmness, whereas previously they might just have been good at appearing calm:

'Whereas before I was trying to be calm on the outside, and I was the, you know, the beautiful swan paddling like mad under the water, now I am a gliding swan' (Rebecca). 
It could also make running a clinic, or carrying out mundane tasks like writing labels on blood bottles, surprisingly relaxing:

'I find sometimes doing my clinic a bit of a relief... as much as I love students and everybody else it's... I feel like a, like a parent sometimes? Your children are constantly 'Mum, Mum, Mum, Mum, Mum' and then you come to work for that break? I go to clinic for that break!' (Ellie).

\section{Stepping back}

When faced with stressful or challenging situations, participants described using mindfulness to 'Take time out in your mind' (Emma):

'Things don't need to be done so quickly and now. Um, you know, you can, you can take a step back and allow yourself to look at what's happening before you can then, um, address it' (Ellie)

This enabled people to distance themselves from their emotional responses to events, and avoid absorbing and feeding off other peoples' stress:

'If you do find colleagues being abrupt or, a bit stress then, you know, you can try not to take it too personally, because you have to, on the whole, um, assume that it is their stuff, and that they're stressed, and um that's why it's coming out in the way it is' (Nadia).

Participants were also able to take a more reflective approach to their own stress reactions. It was evident that a heightened awareness of their own habitual responses had led them to consider how these impacted on those around them. Emma described herself as being 'more thoughtful', while Rebecca and Ellie described how they now took time to calm themselves, rather than dealing with anxiety by verbalising it and '[passing] it on to somebody else, [so] you won't feel it any more' (Rebecca):

'Now I just find it a little bit easier just to sit down first and think about it, rather than then spouting what, what just happened... it probably allows [other people], certainly if, if they've shared the same experience as me, it just allows them to [pause] to just realise what's just happened, and adjust to 
the situation. Whereas before previously I would probably of just verbalised it, quite quickly. And then so I put my pressures onto them' (Ellie).

Rebecca described the ability to step back and stop the mind ruminating over events as a 'freedom' that had released her from years of angry and negative thinking:

'Because I was somebody who would get very cross about things, and then really worry that I'd upset the people around me, by being cross. And then l'd go home and worry about it for about 12 hours afterwards. I don't do that anymore...It's a freedom'.

\section{Taking control}

A heightened awareness of the self within the present moment enabled participants to exercise more control over their time and emotions. Control was felt to be a necessary prerequisite to coping and working well:

'When my anxiety or stress levels get too high, then I do start to feel out of control, and that's when things start to, um, go a little bit wrong... [Mindfulness] gives me an element of control' (Sophie).

'It helps you deal with certain situations... the ability to calm yourself just makes you deal with stressful situations in a much much better way. Because if you can control your own emotions... I find it's, easier to cope with other things that are going on around you' (Jade).

Acting mindfully created a space within which participants were able to think more clearly and make better decisions. Rebecca, for example, described how she was better able to handle time pressures in a busy clinic by suggesting to a woman who needed more time that she go and do some shopping and come back at the end of the clinic:

'We've all done an antenatal clinic where the first person through the door has got a 15/20 minute appointment and dissolves, and needs 50 minutes. And you're thinking 'oh crikey, all these people are waiting', and, and whereas that would have really, really - I probably wouldn't have given that 
woman everything she needed... I still manage my time, but I can switch off, deal with her, and it's like you know 'they're still there, nobody's died, we can deal with this".

Calmness and clarity of thought were seen as particularly valuable by participants who were in a management role:

'in my role as manager, it's come into play, because I actually have taken some time out to think 'right, just - come away, don't respond immediately'... taking that time out before making a decision I think, is where it's helped' (Gill).

Managers also felt they were better able to plan ahead and tackle ongoing issues:

'It's helped me - plan [pause], be maybe more forward thinking... So addressing situations before they arise... rather than just putting things to the back of your mind, is actually just thinking 'this needs to be sorted, so let's just get on and do it'. Sometimes when there's so much going on, it's just easy just to push those problems around' (Sophie).

This quote from Sophie illustrates how mindfulness was used as a tool for confronting and dealing with problems in the workplace, rather than simply enabling her to cope with the status quo.

\section{Reconnecting}

Somewhat paradoxically, a heightened awareness of self and the boundaries of self enabled participants to re-connect with their colleagues, workplace and the women in their care. This reconnection was further facilitated by an emphasis within Mindfulness on kindness to oneself and others. There are three sub-themes in 'reconnecting': 'nurturing the self', 'reconnecting with colleagues', and 'reconnecting with work and women'.

\section{Nurturing the self}


Focussing in and observing their own thoughts and feelings led participants to re-evaluate some of the things they did both in and outside work:

'You might think 'actually, you know, I don't really, I don't know why I do this!' [laughter]...

So then you can make changes you know that, for, for the better really' (Jade).

Self-care was felt to be a key message from the Mindfulness course and participants described applying this at work:

'You can notice you're letting your shoulders drop, releasing tension, um, hopefully it means that you're not going to be quite so tired in the shift because, you know, you've done something to nourish yourself' (Nadia).

A number of participants also described using Mindfulness techniques to help manage physical complaints such as migraines, chronic pain, high blood pressure and insomnia:

I've had sort of situations where l've ...developed a migraine at work, or it's been coming on at work, and thinking 'oh God here we go, it's happening again' ... now I can think 'well actually, it's happening again'...and using the sort of meditation techniques to just sort of accept that it's there, you know, and work with it (Gill).

\section{Reconnecting with colleagues}

Work was experienced as a stressful, demanding and emotionally draining environment where the more junior members of staff in particular felt that they did not always receive sufficient support:

'Working as a qualified midwife initially was just awful - I felt sick coming in to work every day' (Jade).

Attending a Mindfulness course with a group of previously known or unknown colleagues initiated a process of group bonding which participants found incredibly supportive and beneficial. Some even 
questioned whether it was this, rather than the content of the sessions, which made the course effective:

I'm not sure I'd put that [change in workplace culture] down to mindfulness itself, or whether I would put it down to the fact that we just did something as a group - whether it was more about that team bonding, team support kind of thing' (Gill).

Getting to know people and feeling supported, included and accepted by them broke down barriers and engendered a sense of belonging for both new and more experienced members of staff:

'You had students, you had senior management, you know, [University] people. It was nice... there is a kind of, you know, when you sort of bump in to people who did it [Mindfulness course]... there's some little understanding that we've been through something together' (Nadia).

'A few sessions we all got quite giggly because of what we had to do ... it was really nice - I did used to enjoy going to the sessions' (Ellie).

The group also provided a safe space for discussion, and motivated participants to practice and keep going when they came across challenges:

'And if there was someone quite closed to it, or if I was closed to it, then there's always someone there to challenge you... So I think it's being in the group and doing the course, helps you to continue' (Sophie).

For some, simply sitting in companionable silence was calming and restorative:

'I enjoyed the time that we just sat, in silence, as well. I really enjoyed that. And just sitting in silence, you never get a chance to do that... and that was peaceful in itself, you know' (Phoebe). Participants tried to carry their experiences of group support from the course into practice, and recognised that positive relationships with colleagues were a fundamental part of improving 
workplace culture. Ellie felt that her increased calmness and focus had made her more supportive of colleagues:

'I think I am being more - no, I know I'm being, I'm being more supportive. Especially to the um team members... I know I'm not, um, as - short as I used to be'.

This had led to her becoming an important source of support for junior staff - a role that had boosted her confidence and job satisfaction:

'I find that, certainly again the Preceptees, they, they're coming to me, more. I'm, sometimes it can feel a bit as if it's only me they're coming to, but it's [laughter], yea [more laughter]...it can be a bit overpowering sometimes, but, um, I like it as well because it is, it's nice to feel that they can come to me for help and support. So yea... they didn't used to do that'.

Increased empathy and caring within teams was felt to have the potential to have a huge impact on stress, and to effect staff retention and enjoyment of their work:

'I have noticed a really good rapport, um, you know, between - midwives looking out for each other and, and I think sometimes that's a really pleasant bit of the job. Because the women, you know, they're busy having a baby, they're not looking out for you...so, it's the colleague saying 'how's your night going' ... showing some interest, and being willing to help you... I think that really helps when you have that nice support from your colleagues' (Nadia).

As a newly qualified midwife, Nadia recognised that building relationships with colleagues was a key part of feeling confident and at home in her new role:

'As you build up those relationships and feel... more comfortable in the team and everything, then of course it's gonna feel like a more um [pause] a more wholesome environment to go into, you know - it doesn't feel so alien'. 
Mindfulness brought a renewed enjoyment and satisfaction with work to some of the more experienced participants:

'It sort of does make you kind of think back to sometimes why you're doing the job, what you really like about it' (Gill).

It also helped some participants experience work as more meaningful. Sophie described how 'When you're in the middle of things... that day in day in, sort of daily grind that you can have, then, um, sometimes you can actually sort of close down to things... just be 'I've got to start this shift and get to the end of it,'... and the bit in between gets a bit lost I think. So probably I would say [pause] I'm able to track that in between a little bit better, and make it a bit more meaningful'.

Most participants perceived that Mindfulness had enabled them to provide better care. In particular, an increased ability to focus on the present moment meant that they had more time for women and gave them their full attention:

'I can focus on the woman that I'm with. 'Cos before, I was probably so worried about missing something outside that actually I... my stress levels were just going up, and that poor woman that I was with probably was thinking 'oh my God, get that midwife away from me!' [Laughs]' (Sophie). Remaining calm and focused was perceived to make women feel listened to:

'Where I have a better ability to focus on the now, I think it makes [women] feel, um, [pause] like I'm, I'm listening, you know. So that then makes them feel better, because there's nothing worse than talking to somebody who obviously is not paying any attention to you' (Jade).

It was also perceived to enable women to become or remain calm:

'They become stiller... I'm not rattled and so they're not, they're perfectly calm, they're fine... so it's definitely benefitted that. Definitely' (Rebecca). 
Furthermore, the midwives described remembering more of what was being said, and picking up on non-verbal cues. This led them to prioritise relational and emotional aspects of care ahead of performing tasks:

'I think there are some very efficient colleagues around, who are very good at ticking boxes, and at making sure everything's done, but actually at what cost? 'Cos... those women end up [at counselling service]. 'Cos they don't feel cared for, and they feel that things have gone wrong because they weren't cared for' (Rebecca).

Participants considered that introducing mindfulness to women might help further refocus care from information-giving to emotional support:

'Antenatal education is all based around ... bombarding them with information, whereas there's not very much that is just for the mind' (Phoebe).

Where women wanted to use mindfulness or other, similar, techniques in labour, it was felt that having a midwife who had the same training would be beneficial. Understanding the purpose and benefits of mindfulness also enabled even Petra, who felt she had not benefitted personally from the training, to recommend it to women:

'Well I've recommended the course. You know I don't, I don't disbelieve it works ... for some people, particularly people who are anxious I think it's probably very good' (Petra).

Some participants, such as Gill, were not aware of behaving any differently when providing care:

I'm not consciously aware of any sort of conscious decision to use mindfulness while I'm with any women, I don't think'.

She still felt, however, that happier midwives would provide better care: 
'If you can keep the midwives happy it should, it would automatically then by default keep the, um, the women happy 'cos the, if you've got a stressed out sort of pulling your hair out midwife then she's not gonna provide the best care for women (Gill).

\section{Moving forward with confidence}

The control and connectedness brought by incorporating elements of Mindfulness into their lives enabled the participants to face the future with confidence:

'I think just making yourself spend some time everyday just concentrating on being calm actually enables you to do anything really' (Rebecca).

Mindfulness had given participants the tools to survive and thrive in a challenging environment:

'I think it makes me more sustainable as a midwife. ... If you felt stressed all the time... and never replenished yourself with some of the Mindfulness activities, then, you know, I think you'd burn out really quickly, and give up. And so I think it makes me, you know, more of a long term bet, hopefully' (Nadia).

'I don't feel as stressed, and as wound up and tight. Um, yea, I didn't realise how tight I was until I started the course... I really could just feel - certainly after the sessions - just feel the tension leaving me' (Ellie).

The positive effects of mindfulness made the participants keen that it should be available to other people both in their home and working lives:

'I've told [my children] to do things like that before their exams. You know, just focus on, um, on how you feel, you know, getting grounded, make sure your feet are firmly on the floor' (Jade).

Mindfulness was believed to have the potential to effect a positive, lasting and ultimately selfsustaining change on the midwifery workplace environment: 
'If it can reduce stress levels across the board as we're sort of suggesting it can, and depression levels, and resilience can be improved, and that has a positive effect on sick levels, and sickness rates, then the sheer weight of numbers means that your stress is reduced further, 'cos obviously as you know - you have one person go off sick on a busy ward it doubles the workload for other people doesn't it?' (Gill).

Thus, while it was felt that Mindfulness 'may not be for everybody...everybody should give it a go' (Rebecca).

Ellie, Rebecca and Jade all thought that mindfulness should be offered as part of midwifery training:

'Maybe introducing it into, um, training. So the students err, it's, it's done as part of your practice, rather than 'here's an opportunity for you to try'... and maybe if it's something that, that midwives are doing naturally... when they have to deal with stressful situations, they just find it a little bit easier to, to manage it. Whether it be writing assignments or, or having to deal with a shift on [Labour Ward]' (Ellie).

Jade thought that students would also be more receptive to Mindfulness. She perceived that qualified Midwives were more resistant to change, and might feel that they were being offered the training because their practice was deficient in some way.

\section{DISCUSSION}

This is the first qualitative study specifically to explore the impact of Mindfulness training on midwifery practice (the experiences of midwives and nurses have been studied together in an Australian study by Foureur and colleagues (Foureur et al 2013)). Results show that while some participants initially found aspects of the course challenging, those that committed to the concept gained an increased awareness of self and of the self as a situated entity which gave them a sense of control, and enabled them to reconnect with themselves, their colleagues, work and the women they cared for, and to face the future with confidence and positivity. While these findings echo many 
of the conclusions of a small but growing corpus of qualitative work investigating nurses' and other health professionals' experiences and use of Mindfulness (Guillaumie et al., 2016; L. Hunter, 2016), the overriding importance of positive workplace relationships, the apparent ability of Mindfulness to enable these, and the role of increased awareness of situatedness in enabling changes in behaviour and attitude, are new. The findings also suggest there may be a dose-response relationship to Mindfulness practice, in that the more participants practiced the greater the perceived benefits became; and indicate that in order to sustain the benefits of Mindfulness, ongoing support in the form of top-up or refresher sessions at work would be necessary. These suggestions would need to be confirmed in quantitative studies.

The participants' initial scepticism about practising Mindfulness is consistent with change theory, which suggests that any change, even a potentially beneficial one, causes stress and requires a measure of readjustment (Curtis \& White, 2002). Uncertainty and anxiety were apparent as the participants were challenged to 'unfreeze' the existing status quo, including letting go of current coping mechanisms, before learning new ways of coping and endeavouring to incorporate these into their day-to-day lives (Cummings, Bridgman, \& Brown, 2016). The 're-freezing' stage of Lewin's seminal change model is evident in participants' desire for regular Mindfulness refresher sessions. It has been noted that Midwives and other health professionals can be particularly resistant to change, perhaps owing to the constant changes imposed in busy and stressful healthcare settings (Hunter \& Warren, 2014). A perceived lack of control over their working environment is also known to predispose people to being particularly resistant to change (L. Hunter et al., 2015). The apparent ability of Mindfulness to give participants a sense of control at work is therefore significant, and suggests that the practice may help midwives make more positive adjustments to other workplace changes.

Lack of control is also known to be a significant cause of stress, both within midwifery and other settings (L. Hunter et al., 2015; Kirkham, 2010). It has been observed to lead to coping mechanisms 
such as reductionism and task-orientation, as stressed midwives attempt to exert control over aspects of their working day (L. Hunter et al., 2015). Participants in the current study noted that they 'shut down' while working, and referred to the 'tick-box' approach of some of their colleagues; it is evident that they felt that practising Mindfulness enabled them to adopt a more relational approach. A positive midwife-woman relationship underpinned by kindness and an individualised approach has been identified as a hall mark of good care (National Maternity Review, 2016).

The quality of relationships between colleagues are increasingly recognised to reflect the care that is then given to women (B. Hunter et al., 2008). Poor and destructive relationships between midwives have been attributed to their being an oppressed group, and again reflect a lack of control over their working environment (Kirkham, 1999). The self as a relational being who can only achieve fulfilment through positive relationships is a theme present in the works of the Brazilian educator and philosopher Paulo Freire, and the American philosopher and gender theorist Judith Butler. The works of both are relevant to midwifery because they write about ways in which oppressed groups can become liberated. Freire in particular writes about how oppressed groups tend to internalize the values of their oppressors, resulting in low self-esteem and the directing of frustration and anger against one another (Freire, 1994). This behaviour prevents the development of a sense of unity and cohesiveness necessary to enact change, meaning oppressive systems remain unchallenged (Freire 1994, Roberts et al 2009).

Mindfulness, in particular learning Mindfulness as a group, appears to offer a possible way of challenging the prevailing hegemony within maternity care. The positive relationships and increased self-efficacy and confidence gained by attending a Mindfulness course enabled a renewed connectivity which in turn led to a perception of being better midwives and more content people. Judith Butler wrote that 'no human can be human alone' (Butler, 2011, p7), while Freire noted that developing a sense of connection and pride in the abilities of one's group is one of the precursors to enacting positive change (Freire, 1994). In nursing research, there is some indication that group 
interventions such a writing group enabled nurses to feel empowered and find a 'voice', while a lack of support among nurses in the workplace has been linked to low satisfaction and poor performance (Roberts et al 2009). Levels of burnout among midwives have been found to be lessened by the presence of social support at work (Kalicinska, Chylinska, \& Wilczek-Rozyczka, 2012).

Workplace bullying has been identified as a major reason for midwives and nurses leaving the profession. It has been suggested that students and newly qualified midwives and nurses are particularly at risk, and data indicates that an unacceptably high number of newly qualified midwives quit the profession in the first year of practice (Killingley, 2016). Incorporating Mindfulness training into pre-registration education programmes may enable newly qualified midwives to develop the resilience needed to make a successful transition to qualified practitioner.

As well as enabling midwives to cope with the status quo, Mindfulness gave them tools to work towards change. It is important to recognise that whilst it can reduce stress and reconnect and reorientate midwives, Mindfulness is not of itself an answer to chronic understaffing and high workload. Rather, it creates a space where change can happen (for Butler, this space is created by the relationships between people). Material improvements still need to be fought for.

\section{LIMITATIONS}

This study was conducted on a single site, and participants were self-selecting. However, a range of views and experiences was expressed by experienced and newly-qualified midwives working in different environments. The findings may not be transferable to other settings, although they do resonate with philosophical theory and with findings from related studies in different health care settings. Despite steps being taken to reduce the influence of the principle investigator on the findings, they may nonetheless be influenced by her particular worldview. The small sample size was appropriate for the chosen methodology.

\section{CONCLUSION}


An in-depth analysis of midwives' perceptions of the impact of a Mindfulness course on their practice has shown that Mindfulness can offer an effective answer to some of the challenges facing the profession, such as high levels of stress, role dissatisfaction and workplace bullying. The pivotal roles of control and positive relationships in this process resonate with other nursing and midwifery studies, and with contemporary philosophical thought.

\section{RELEVANCE FOR CLINICAL PRACTICE}

Further qualitative and larger-scale quantitative research is necessary to substantiate the findings of this study. However, it adds to a body of evidence which suggests more should be done to foster and encourage supportive relationships amongst midwifery and other healthcare colleagues, and to give them tools to cope with the stressful environment in which they work. In particular, Mindfulness confers a sense of control, enabling midwives to provide relational and individualised care. There is thus an argument for building Mindfulness techniques into midwifery curricula, particularly in view of the high numbers of midwives who leave the profession within a year of qualifying; and for encouraging midwives who have been trained in Mindfulness to continue to practice the techniques through providing regular refresher sessions.

Word count: 7445 


\section{REFERENCES}

Beck, C. T., LoGiudice, J., \& Gable, R. K. (2015). A mixed-methods study of secondary traumatic stress in certified nurse-midwives: shaken belief in the birth process. Journal of Midwifery \& Women's Health, 60(1), 16-23. http://doi.org/10.1111/jmwh.12221

Brocki, J. M., \& Wearden, A. J. (2006). A critical evaluation of the use of interpretative phenomenological analysis ( IPA ) in health psychology. Psychology and Health, 21(1), 87-108. http://doi.org/10.1080/14768320500230185

Butler, J. (2011). Bodies in alliance and the politics of the street. Retrieved April 19, 2017, from http://www.eipcp.net/transversal/1011/butler/en

Chiesa, A., \& Serretti, A. (2009). Mindfulness-based stress reduction for stress management in healthy people: a review and meta-analysis. Journal of Alternative and Complementary Medicine (New York, N.Y.), 15(5), 593-600. http://doi.org/10.1089/acm.2008.0495

Cummings, S., Bridgman, T., \& Brown, K. G. (2016). Unfreezing change as three steps: Rethinking Kurt Lewin's legacy for change management. Human Relations, 69(1), 33-60. http://doi.org/10.1177/0018726715577707

Curtis, E., \& White, P. (2002). Resistance to change: causes and solutions. Nursing Management, 8(10), 15-20. Retrieved from http://journals.rcni.com/doi/pdfplus/10.7748/nm.8.10.15.s8

Foureur, M, Besley, K, Burton, G, Yu, N, \& Crisp, J. (2013). Enhancing the resilience of nurses and midwives: pilot of a mindfulness-based program for increased health, sense of coherence and decreased depression, anxiety and stress. Contemporary Nurse, 45(1), 114-125.

Freire, P. (1994). Pedagogy of Hope. London: Bloomsbury.

Guillaumie, L., Boiral, O., \& Champagne, J. (2016). A mixed-methods systematic review of the effects of mindfulness on nurses. Journal of Advanced Nursing, (September). http://doi.org/10.1111/jan.13176

Harden, A., \& Health, F. (2010). Mixed-Methods Systematic Reviews: Integrating Quantitative and Qualitative Findings. Focus: A Publication of the National Center for the Dissemination of Disability Research, (25), 108.

Hunter, B., Berg, M., Lundgren, I., Ólafsdóttir, Ó. Á., \& Kirkham, M. (2008). Relationships: The hidden threads in the tapestry of maternity care. Midwifery, 24(2), 132-137. http://doi.org/10.1016/j.midw.2008.02.003

Hunter, B., \& Warren, L. (2014). Midwives' experiences of workplace resilience. Midwifery, 30(8), 926-934. http://doi.org/10.1016/j.midw.2014.03.010

Hunter, L. (2016). Making time and space : the impact of mindfulness training on nursing and midwifery practice . A critical interpretative synthesis, 1-12. http://doi.org/10.1111/jocn.13164

Hunter, L., Magill-Cuerden, J., \& McCourt, C. (2015). “Oh no, no, no, we haven't got time to be doing that": Challenges encountered introducing a breast-feeding support intervention on a postnatal ward. Midwifery, 31(8), 798-804. http://doi.org/10.1016/j.midw.2015.03.006

Kalicinska, M., Chylinska, J., \& Wilczek-Rozyczka, E. (2012). Professional burnout and social support in the workplace among hospice nurs...: EBSCOhost. International Journal of Nursing Practice, 18, 595-603. Retrieved from http://web.a.ebscohost.com.oxfordbrookes.idm.oclc.org/ehost/pdfviewer/pdfviewer?sid=85e2 1938-f71b-4532-b8ee-760d018f7f42\%40sessionmgr4010\&vid=1\&hid=4207 
Killingley, J. (2016). Why re you leaving, you only just got here? An examination of attrition in preregistration and preceptorship midwives. Midwives. Retrieved from https://www.rcm.org.uk/news-views-and-analysis/analysis/training-for-resilience

Kirkham, M. (1999). The culture of midwifery in the National Health Service in England. Journal of Advanced Nursing, 30(3), 732-9.

Kirkham, M. (2010). We need to relate. In M. Kirkham (Ed.), The midwife-mother relationship (Second, pp. 250-271). Basingstoke: Palgrave Macmillan.

Ludwig, D. S., \& Kabat-Zinn, J. (2008). Mindfulness in medicine. JAMA, 300(11), 1350-2. http://doi.org/10.1001/jama.300.11.1350

Majhenic, J., \& Mivsek, A. (2012). Mobbing in midwifery. Obzornik Zdravstvene Nege, 46(2), 165170. Retrieved from

http://web.a.ebscohost.com.oxfordbrookes.idm.oclc.org/ehost/detail/detail?sid=b2163686cf1a-45d8-b5a0-

f750d18eb589\%40sessionmgr4006\&vid=0\&hid=4207\&bdata=JnNpdGU9ZWhvc3QtbG|2ZQ\%3D $\% 3 D \# A N=108138510 \& d b=\operatorname{cin} 20$

Mckenna, L., \& Boyle, M. (2016). Midwifery education in practice Midwifery student exposure to workplace violence in clinical settings: An exploratory study. http://doi.org/10.1016/j.nepr.2015.11.004

Mollart, L., Skinner, V. M., Newing, C., \& Foureur, M. (2013). Factors that may influence midwives work-related stress and burnout. Women and Birth, 26(1), 26-32.

http://doi.org/10.1016/j.wombi.2011.08.002

National Maternity Review. (2016). BETTER BIRTHS Improving outcomes of maternity services in England A Five Year Forward View for maternity care. Retrieved from https://www.england.nhs.uk/wp-content/uploads/2016/02/national-maternity-reviewreport.pdf

Pringle, J., Drummond, J., Mclafferty, E., \& Hendry, C. (2011). Interpretative phenomenological analysis : a discussion and critique. Nurse Researcher, 18(3), 20-24.

Pugh, J. D., Twigg, D. E., Martin, T. L., \& Rai, T. (2013). Western Australia facing critical losses in its midwifery workforce: A survey of midwives' intentions. Midwifery, 29(5), 497-505. http://doi.org/10.1016/j.midw.2012.04.006

Roberts, S., Demarco, R., \& Griffin, M. (2009). The effect of oppressed group behaviours on the culture of the nursing workplace: A review of the evidence and interventions for change. Journal of Nursing Management, 17(3), 288-293. http://doi.org/10.1111/j.13652834.2008.00959.x

Roberts, T. (2013). Understanding the research methodology of interpretative phenomenological analysis. British Journal of Midwifery, 21(3), 215-218.

Robertson, J. H., \& Thomson, A. M. (2014). A phenomenological study of the effects of clinical negligence litigation on midwives in England: The personal perspective. Midwifery, 30(3), e121-e130. http://doi.org/10.1016/j.midw.2013.12.003

Royal College of Midwives. (2016). Caring for You Campaign : Survey Results RCM campaign for healthy workplaces delivering high quality care. London.

Sato, K., \& Adachi, K. (2013). Occupational stress experienced by Japanese midwives. British Journal of Midwifery, 21(11), 801-806. http://doi.org/10.12968/bjom.2013.21.11.801 
Smith, J., \& Osborn, M. (2008). Interpretative phenomenological analysis. In J. Smith (Ed.), Qualitative Psychology: a practical guide to methods (2nd ed., pp. 53-80). London: Sage Publications.

Tariq, S., \& Woodman, J. (2010). Using mixed methods in health research. Journal of the Royal Society of Medicine Short Reports, 1-8. http://doi.org/10.1177/2042533313479197

Warriner, S., Hunter, L., \& Dymond, M. (2016). Mindfulness in maternity : Evaluation of a course for midwives. British, 24(3), 2-9.

Williams, M., \& Penman, D. (2011). Mindfulness : a practical guide to finding peace in a frantic world. Piatkus. 
TABLES

Table 1. Participant profiles

\begin{tabular}{|c|c|}
\hline Pseudonym & Profile \\
\hline Emma & $\begin{array}{l}\text { An experienced midwife working part time in a predominantly management role. } \\
\text { Being able to attend a mindfulness course made her feel valued and cared for as an } \\
\text { employee. The importance of self-care was a recurrent theme in her narrative, as } \\
\text { was an increased focus on others and how they might be feeling. Since finishing the } \\
\text { course, Emma has not done any formal meditation practice, but uses mindfulness } \\
\text { techniques on about } 5 \text { days each week. }\end{array}$ \\
\hline Gill & $\begin{array}{l}\text { An experienced midwife and midwifery team leader. She attended a mindfulness } \\
\text { course with her team. Gill felt that the course had brought the team closer together } \\
\text { and improved the workplace culture. A major theme running through her narrative } \\
\text { was that mindfulness gave people the capacity to have 'time off' from feeling } \\
\text { stressed. She also spoke of improved physical wellbeing. After attending the course, } \\
\text { she was motivated to undertake further mindfulness training. At the time of her } \\
\text { interview, Gill was still making time to practice meditation every day. }\end{array}$ \\
\hline Ellie & $\begin{array}{l}\text { An experienced community midwife working part time. She was part of a } \\
\text { supportive and enthusiastic Mindfulness group. Ellie described how, before the } \\
\text { course, she was constantly on the go; Mindfulness had enabled her to slow down } \\
\text { and take stock. She felt that she was also more aware of and supportive of others, } \\
\text { particularly the junior members of her team. She still practices mindfulness at home } \\
\text { a minimum of three times a week. }\end{array}$ \\
\hline Jade & $\begin{array}{l}\text { A newly-qualified midwife working full time on Labour Ward. She attended a } \\
\text { mindfulness course towards the end of her midwifery training. Although she was } \\
\text { initially sceptical and found aspects of the course challenging, it highlighted to her } \\
\text { just how much her mind wandered and the extent to which she was not therefore } \\
\text { present in her life. Jade kept returning to the concept of grounding. She uses the } \\
\text { breathing techniques she learnt on the course 'all the time, pretty much'. }\end{array}$ \\
\hline Nadia & $\begin{array}{l}\text { A newly qualified midwife working } 30 \text { hours a week in the community and on labour } \\
\text { ward. She attended a course while still a student. She was familiar with mindfulness } \\
\text { before going on the course. Nadia initially felt overwhelmed as she made the } \\
\text { transition from student to midwife, and has used mindfulness to retain a sense of } \\
\text { self, cope with the unknown and avoid becoming task-focused in her work. She } \\
\text { often does her mindfulness practice while travelling to work. }\end{array}$ \\
\hline Petra & $\begin{array}{l}\text { An experienced full-time community midwife. She attended the mindfulness course } \\
\text { put on for her team. She didn't engage whole-heartedly in the course or do any of } \\
\text { the home practice. She recognised the potential of mindfulness for reducing stress } \\
\text { in midwifery teams, and was recommending the course to women. }\end{array}$ \\
\hline Phoebe & $\begin{array}{l}\text { A full time community midwife who has been qualified for around } 10 \text { years, and } \\
\text { also attended a mindfulness course as part of a team. She had several difficulties } \\
\text { with the concept of mindfulness and did not engage completely with the course } \\
\text { (she only attended half the classes) as it happened at a busy time in her life. She }\end{array}$ \\
\hline
\end{tabular}




\begin{tabular}{|l|l|}
\hline & $\begin{array}{l}\text { believed that mindfulness could help her relax and slow down the 'monkey chatter' } \\
\text { in her head, and intended to go back to it in the future. }\end{array}$ \\
\hline Rebecca & $\begin{array}{l}\text { An experienced midwife currently delivering antenatal care and post birth } \\
\text { counselling. She had some previous experience of mindfulness, but described the 8- } \\
\text { week course as 'life changing'. She spoke of how her newly-found calmness enabled } \\
\text { her to give better care, as she was less rattled by the negative emotions of women } \\
\text { or her colleagues. She practices mindfulness at least once a week, especially in } \\
\text { order to help her cope with chronic back pain. }\end{array}$ \\
\hline Sophie & $\begin{array}{l}\text { Has been qualified for just under ten years, and is the manager of a busy ward. } \\
\text { Although initially sceptical, she was impressed that she found herself able to } \\
\text { incorporate mindfulness into her working life, and felt that this marked it out from } \\
\text { other meditation courses she had done. She practices mindfulness at home 'on and } \\
\text { off', but particularly uses it on busy shifts at work. }\end{array}$ \\
\hline
\end{tabular}

Table 2. Themes identified.

\begin{tabular}{|l|l|}
\hline Superordinate theme & Sub-themes \\
\hline Being challenged and committing & Discomfort \\
& Keeping going \\
\hline Containing the self & Centring the self \\
& Focussing \\
& Stepping back \\
& Taking control \\
\hline Reconnecting & Nurturing the self \\
& Reconnecting with colleagues \\
& Reconnecting with work and women \\
\hline Moving forward with confidence & \\
\hline
\end{tabular}

